https://www.journal-imab-bg.org

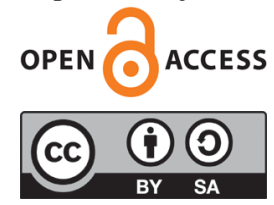

Original article

\title{
SIMILARLY HIGH SEROPREVALENCE OF ANTI- HELICOBACTER PYLORI ANTIBODIES IN MEN AND WOMEN WITH AND WITHOUT IDIOPATHIC INFERTILITY
}

\author{
Pavlina Andreeva-Gateva ${ }^{1}$, Anna Masseva ${ }^{2}$ \\ 1) Department of Pharmacology and Toxicology, Medical Faculty, Medical Uni- \\ versity of Sofia, Bulgaria. \\ 2) University Hospital of Obstetrics and Gynecology “Maichin Dom”, Bulgaria, \\ Sofia, Bulgaria.
}

\begin{abstract}
:
Our study aimed to compare the seroprevalence of anti-Helicobacter pylori antibodies in patients with and without unexplained infertility. Three groups were compared, i.e., patients with idiopathic infertility (Group A, $\mathrm{n}=105$ ); fertile patients with Helicobacter pylori-associated diseases (Group B, n=105) and fertile subjects lacking H. pylori-related disease (Group C, $n=105$ ). Antisperm antibodies (ASA) and anti- H. pylori antibodies (AHPA) were evaluated. Similarly high seroprevalence of AHPA in all studied patients was found $(\mathrm{p}>0.05)$. Odds ratio calculated against infertility for AHPA-positive patients was 0.97 (95\% confidential interval from 0.57 to 1.68, $\mathrm{p}=0.113$ ). The AHPA-seroprevalence of samples from men was 1.3 - 1.8 times higher than those from women. Also, for ASA-seroprevalence, the men-to-women ratio was up to 2 times higher. We calculated the odds ratio for male and female groups separately and again did not obtain statistical significance in the odds ratios neither for men nor for women. Our findings failed to reveal H. pylori seropositivity as a possible risk factor for idiopathic infertility neither in men nor in women.
\end{abstract}

Keyword: anti-Helicobacter pylori antibodies, antisperm antibodies, idiopathic infertility,

\section{INTRODUCTION}

Infertility is a condition that affects about $15 \%$ of couples who attempt to conceive and is defined as the lack of conception after an arbitrary period of 12 months without using any contraception [1]. Nearly $10 \%$ of infertile patients of all aetiologies are positive by circulating anti-sperm antibodies (ASA), and ASA prevalence probably increases with the patient's age [2]. Notice that $1-2.5 \%$ of fertile men also present with ASA [3].

In about $25 \%$ of couples, infertility is unexplained, with no identified male or female cause [4]. The rate of infertility of the immune origine varies depending on the method of evaluation and probably from the evaluated population. The term immune infertility is used if spontaneously occurring antibodies binding to antigens of the gametes impair sperm-oocyte interaction [5]. So far, ASA has been observed more frequently than anti-oocyte antibodies.Rumke and Hellinger [6] firstly described ASA. It was proven to have cytotoxic, immobilizing, and agglutinating functions, and to be implicated in the pathogenesis of immune infertility via several mechanisms, i.e., decreased superoxide dismutase, nitric oxide synthase, and acrosin activity [7, 8]. The presence of ASA is associated with the developmental or acquired abnormalities of the structure of the blood-testis barrier [9]. ASA formation affects sperm motility, cervical mucus penetration, zona binding, zona penetration, oolemma binding, and pronucleus formation. Among the risk factors for ASA production, inflammatory diseases due to infections with different localization are believed to play an important role.

Helicobacter pylori is a gram-negative, microaerophilic, and spiral-shaped bacterium with its niche in the stomach. It can cause chronic gastritis, peptic ulcer disease, mucosa-associated lymphoid tissue (MALT) lymphoma and are considered the leading risk factors for developing gastric cancer [10]. The infection is commonly acquired during infancy, and the first contact of susceptible individuals with this organism results in acute gastritis. In the last two decades, several extragastric manifestations have been attributed to this bacterium, but only for some, a role has been proved [11].

Rising evidence in the literature suggests that even the reproductive sphere seems to be negatively influenced by $H$. pylori infectious status [12]. The prevalence of H. pylori infection in infertile couples is higher than in healthy blood donors. The spermatozoa's beta-tubulin and the proteins of $\mathrm{H}$. pylori (flagellin, vacuolating cytotoxin A, and cytotoxin-associated gene A) are homologs [13]. Antigenic mimicry was proposed as a hypothetical mechanism, including in cases with polycystic ovary syndrome with high H. pylori seropositivity [14]. Some au- 
thors argue against the association between chronic inflammatory or infectious diseases of the male reproductive tract and the presence of ASA in semen [15]. We could find only one trial directly testing the effect of specific anti-Helicobacter pylori treatment with omeprazole, tinidazole, and clarithromycin on infertility with promising results [16]. The methodology of this trial was further criticized [17] mainly because of the unprecise detection of $\mathrm{H}$. pylori before and after the treatment.

This study aimed to investigate the seroprevalence of anti-Helicobacter pylori antibodies (AHPA) and antisperm antibodies (ASA) in patients with and without idiopathic infertility.

\section{MATERIALS AND METHODS:}

From January 2013 to December 2013, we evaluated patients contacting two tertiary healthcare settings for infertility evaluation. For this period, a total of 250 patients with a diagnosis of Idiopathic infertility were approached, and 210 (106 women and 104 men) were initially included in our study. Gastroenterologists evaluated patients, and the diagnosis of upper acute gastroduodenal diseases was further excluded or affirmed. Because we also wanted to compare the ASA and AHPA seroprevalence in infertile versus fertile subjects, we further invited for testing individuals with negative biopsy for $\mathrm{H}$. pylori and without infertility. In this case, we approached 108 subjects, and 105 gave their consent.

The local Ethics committee approved the study, and patients signed informed consent. Authors have complied with the World Medical Association Declaration of Helsinki regarding the ethical conduct of research involving human subjects. Patients were questioned about their smoking habits and alcohol consumption. Body mass in$\operatorname{dex}(\mathrm{BMI})$ was assessed according to the formula $\mathrm{BMI}=$ weight (kg)/height2 (m2).

\section{Patients with idiopathic infertility (Group A)}

Data from 105 patients (54 women and 51 men, mean age $38.77 \pm 7.35$ years) tested for infertility were selected. After excluding urological, gynecological, and hormonal causes of infertility, the diagnosis of idiopathic infertility was accepted. The presence of acute gastrointestinal disease was excluded.

Patients with proven $H$. pylori infection (Group B)

Patients with idiopathic infertility suffering from an upper acute gastroduodenal disease (52 women and 53 men, mean age $40.30 \pm 7.35$ years) were included in this group. The diagnosis of $\mathrm{H}$. pylori infection was confirmed with a biopsy. Biopsies were stained with hematoxylin and eosin, Giemsa, and Warthin-Starry and assessed by two independent pathologists.

A control group (Group C)Patients with negative biopsy for H. pylori and without infertility (47 females and 58 males, mean age $39.55 \pm 6.55$ years) were taken as double-negative controls. For groups B and C, we selected patients with their-owns children up to 10 y.o. Also, female partners in the couple were up to 40 y.o.

Blood was collected by venipuncture. Sera were separated by centrifugation, stored at $-20^{\circ} \mathrm{C}$, and evaluated in series with Biotek ELISA reader ELx $800^{\mathrm{TM}}$ (BioTec, USA).

\section{Antisperm antibody (ASA) test}

ASA was evaluated in the serum of the patients with the enzyme-linked immunosorbent assay (ELISA) against sperm antigens. Commercially available anti-spermatozoa antibody (Bioserv diagnostics, Germany) was used according to the manufacturer's instructions. Plates for this ELISA are coated with a mix of spermatozoa proteins. Serum samples are used at a 1:100 dilution and incubated with the antigen-coated plates for one $\mathrm{h}$ at $37^{\circ} \mathrm{C}$. After three washing steps, a second incubation for $60 \mathrm{~min}$ with the enzyme conjugate peroxidase-labeled secondary antibody (anti-IgG conjugate) was performed. Additional five-time washing steps were followed by 30-min incubation in tetramethylbenzidine for color development. The optical density was measured at $450 \mathrm{~nm}$. The cut-off value of $60 \mathrm{U} / \mathrm{ml}$ was used, above which the sample was accepted as decisive.

\section{Anti-Helicobacter pylori antibody (AHPA) test}

ELISA for anti-Helicobacter pylori IgG antibodies was performed using the commercially available test kit recomwell ELISA (Mikrogen, Germany) according to the instructions of the manufacturer. Plates for this ELISA are coated with recombinant cytotoxin-associated gene A factor of virulence cytotoxin-associated gene A (CagA) and the chaperonin GroEL (a conserved, highly immunogenic and a prominent stress response protein). Serum samples are used at a 1:100 dilution and incubated with the antigen-coated plates for one $\mathrm{h}$ at $37^{\circ} \mathrm{C}$. After three washing steps, a second incubation for $30 \mathrm{~min}$ with the peroxidaselabeled secondary antibody (anti-IgG conjugate) was performed. An additional four washing steps were followed by 30-min incubation in tetramethylbenzidine for color development. The optical density (OD) was measured at $450 \mathrm{~nm}$. Positive and negative controls established the cut-off point of OD at 0.250 .

\section{Statistics}

The age and the BMI were presented as mean values \pm standard deviation. Chi-square was used for assessing smoking habits (smoking e" than ten cigarettes/daily), alcohol consumption (e" glass of wine/day), and for assessment of differences in the antibody seroprevalence among the three groups. Odd ratio against infertility for AHPA-positive patients was calculated. The data were processed with the SigmaPlot v12.0 (Systat Software, Inc, USA). Results with $\mathrm{p}<0.05$ two-tailed were accepted as statistically significant.

\section{RESULTS:}

Data for age, BMI, smoking habits, and alcohol consumption habits did not differ among groups (Table $1)$. 
Table 1. Demographics and immunological testing. Data are presented as a mean \pm standard deviation.

\begin{tabular}{llll}
\hline & Group A & Group B & Group C \\
$\mathrm{N}$ & 105 & 105 & 105 \\
\hline Age (years) & $38.77 \pm 7.35$ & $40.30 \pm 7.35$ & $39.55 \pm 6.55$ \\
\hline Women; men (n:n) & $54 ; 51$ & $52 ; 53$ & $47 ; 58$ \\
\hline BMI (kg/m2) & $26.44 \pm 2.13$ & $25.05 \pm 3.33$ & $26.12 \pm 2.70$ \\
\hline Smoking habit & $33(31.43)$ & $37(35.24)$ & $36(34.28)$ \\
$(\geq$ then ten cigarettes/day) $\mathrm{n}(\%)$ & & & \\
\hline Alcohol & $40(38.09)$ & $38(36.19)$ & $44(41.90)$ \\
$(\geq$ glass of wine/day) $\mathrm{n}(\%)$ & & $27(25.71)^{* *}$ & $3(2,88)^{* * *}$ \\
\hline ASA-positive sera $\mathrm{n}(\%)$ & $56(53.33)^{*}$ & $19 / 53(35.85)^{* * *}$ & $3 / 58(5.17)^{* * *}$ \\
- Men $(\%)$ & $37 / 51(72.54)^{*}$ & $8 / 52(15.38)^{* *}$ & $0 / 47(0.00)^{* * *}$ \\
- Women $(\%)$ & $19 / 54(35.18)^{*}$ & $86(81.90)$ & $73(70.19)$ \\
\hline AHPA-positive sera & $79(75,24)$ & $49 / 53(92.45)$ & $51 / 58(87.93)$ \\
- Men $(\%)$ & $49 / 51(96.08)$ & $37 / 52(71.15)$ & $22 / 47(46.81)$ \\
- Women $(\%)$ & $30 / 54(55.56)$ & & \\
\hline
\end{tabular}

$* \mathrm{P}<0.05 \mathrm{~A}$ vs $\mathrm{B} ; * * \mathrm{P}<0.05 \mathrm{~B}$ vs $\mathrm{C} ; * * * \mathrm{P}<0.05 \mathrm{~A}$ vs $\mathrm{C}$

The similarly high seroprevalence of AHPA in all studied patients - Group A (74.53\%), Group B (81.13\%), and Group C (70.19\%) was our main finding ( $>00.05)$. ASA was found to increase as follows: Group $\mathrm{C}<$ Group $\mathrm{B}<$ Group A. Statistically significant higher seroprevalence was detected both in Group A and Group B, as compared with Group C $(\mathrm{P}<0.05)$. Odd ratio calculated against infertility for AHPA-positive patients was 0.97 (95\% confidential interval from 0.57 to $1.68, \mathrm{p}=0.113$ ).

We compared the seroprevalence of ASA and AHPA among patients with idiopathic infertility, patients with $\mathrm{H}$. pylori infection, and the control group. Our finding failed to confirm the implication of $\mathrm{H}$. pylori infection in idiopathic infertility because: (i) the seroprevalence of AHPA did not differ statistically among the three groups, i.e., patients with idiopathic infertility, patients with proved $\mathrm{H}$. pylori infection and control subjects, and (ii) the odds ratio was found to be insignificant 0.97 (95\% confidential interval from 0.57 to $1.68, \mathrm{p}=0.113$ ).

\section{Subgroup analysis}

We noticed that in our study, the AHPAseroprevalence of samples from men was $1.3-1.8$ times higher than those from women. Also, for ASA-seroprevalence, the men-to-women ratio was up to 2 times higher. Our results comply with epidemiological findings, reporting that ASA from infertile men can broadly vary from $7 \%$ to $44 \%$, depending on the method of analysis. In women samples, however, the seroprevalence is always reported significantly lower [18]. To address the possible sex differences, we looked at the male and female groups separately. Again, the odds ratio was found to be insignificant. Odd ration calculated for male group was 2.61 (95\% confidential interval from 0.86 to $7.95, \mathrm{p}=0.09$ ), and for women it was 1.79 (95\% confidential interval from 0.89 to $3.59, \mathrm{p}=0.10)$.

We assessed antibodies against $\mathrm{H}$. pylori with the test capable of detecting the following antigens: cytotoxin-associated gene A (CagA), vacuolating cytotoxin A (VacA), an essential toxin for Helicobacter pylori pathogenesis; urease subunit beta (UreB); heat shock proteins A and B (HspA\&B); flagellin (FlaA) and urease subunit alpha (UreA). We discovered titers above the cut-off value not only in patients with H. pylori-related diseases (Group B) but also in patients without gastrointestinal disease with or without idiopathic infertility (Groups A and C). Moreover, we did not reveal any statistically significant differences in the seroprevalence of AHPA among groups, making the hypothesis about the importance of $\mathrm{H}$. pylori infection for infertility questionable. High prevalence of virulent Helicobacter pylori strains in symptomatic. Our finding extends the observation with the comparably high seroprevalence of anti-Helicobacter pylori antibodies in patients with and without idiopathic infertility.

\section{DISCUSSION:}

Four major types of tests are used in practice to detect and quantify ASA, namely agglutination tests, complement-dependent tests, immunoglobulin-binding, and ELISA tests. Few of them are with a clear target with a known implication in the fertility/infertility, as, i.e., antibodies against actin-like 7 a protein or spermatogenic glyceraldehyde-3-phosphate dehydrogenase [19]. Those tests became available only after we have finished our study. The test commonly used for the diagnosis of immune infertility is the tray agglutination test (TAT), by Friberg in 1974 [20]. We did not evaluate TAT (i) because 
we have focused on idiopathic rather than immune infertility, and (ii) this test is also with undefined molecular targets, and nonimmunological agglutination can interfere with the results.

ASA was found to increase, as follows: Group $\mathrm{C}<$ Group B < Group A. Statistically significant higher seroprevalence were detected both in Group A and Group $\mathrm{B}$, as compared with Group $\mathrm{C}(\mathrm{P}<0.05)$. The high seroprevalence of ASA in our patients with idiopathic infertility is not unexpected because of the inclusion criteria for this group in our study. Interestingly, patients with proven fertility but H. pylori-positive (Group B) also displayed statistically significantly higher ASA seroprevalence, as compared with the control group. We believe that this is another argument making the $\mathrm{H}$. pylori hypothesis of idiopathic infertility less plausible.

\section{Generalisability of the study}

The advantage of our study is that we have compared well-characterized subjects for differences in of seroprevalence. The diagnosis of $\mathrm{H}$. pylori infection was histologically proved. To put the diagnosis of idiopathic infertility, we have excluded urological, gynecological, and hormonal causes, but genetic factors remained unexplored. In our study, we have included patients with idiopathic rather than immune infertility. The ELISA test we used showed the binding of antibodies on the sperm surface, but no antigenic information could be applied. Of note also that, during the ELISA testing, samples were subjected to fixation, disrupting the plasma membrane of spermatozoa, which may result in the detection of internal antigens. Only ASA assays for detecting antibodies directed towards surface antigens have a clinical significance. Subsuperficial antigens cannot be exposed to antibodies by living cells along the male genital tract. Of note also, that a test directly detecting ASA with the known association of the fertility/infertility process would be more informative.

\section{CONCLUSION}

Our findings failed to reveal H. pylori seropositivity as a possible risk factor for idiopathic infertility. We presume that the involvement of $\mathrm{H}$. pylori in infertility if any, is infrequent. More probably, focusing on only one microorganism (H. pylori or other) as a causative factor for infertility has to be shifted to the evaluation of the whole microbiome with the introduction of metagenomics evaluations.
Abbreviations:
AHPA - anti-Helicobacter pylori antibody;
ASA - anti-sperm antibodies;
BMI - Body mass index;
ELISA - enzyme-linked immunosorbent assay;
MALT - mucosa-associated lymphoid tissue

\section{Acknowledgments:}

This work was supported by the Ministry of Education and Science, Bulgaria (DRI-192006).

\section{REFERENCES:}

1. ESHRE Capri Workshop Group. Physiopathological determinants of human infertility. Hum Reprod Update. 2002 Sep-Oct;8(5):435-47. [PubMed] [Crossref]

2. Hossain A, Islam N, Arya S, Madanes A. The prevalence of circulating antisperm antibody (ASA) in the infertile population representing all etiologies. Middle East Fertil Soc J. 2007; 12(1):27-30. [Internet]

3. Chamley LW, Clarke GN. Antisperm antibodies and conception. Semin Immunopathol. 2007 Jun; 29(2):169-84. [PubMed] [Crossref]

4. Investigation of fertility problems and management strategies. In: Fertility: Assessment and Treatment for People with Fertility Problems. National Collaborating Centre for Women's and Children's Health (UK). Royal College of Obstetricians and Gynaecologists. February 2013. Chapter 6. pp.80-130. [PubMed]
5. Bohring C, Krause W. Immune infertility: towards a better understanding of sperm (auto) immunity. The value of proteomic analysis. Hum Reprod. 2003 May;18(5):91524. [PubMed] [Crossref]

6. Rumke P, Hellinga G. Autoantibodies against spermatozoa in sterile men. Am J Clin Pathol. 1959 Oct;32: 357-63. [PubMed] [Crossref]

7. Zhang $\mathrm{H}$, Zhao E, Zhang $\mathrm{C}$, Li $X$. The Change of Semen Superoxide Dismutase and Acrosin Activity in the Sterility of Male Patients with Positive Antisperm Antibody. Cell Biochem Biophys. 2015 Nov;73(2): 451-453. [PubMed] [Crossref]

8. Zhao Y, Zhao E, Zhang C, Zhang H. Study of the Changes of Acrosomal Enzyme, Nitric Oxide Synthase, and Superoxide Dismutase of Infertile Patients with Positive Antisperm Antibody in Seminal Plasma. Cell Biochem Biophys. 2015 Dec;73(3):

\section{9-42. [PubMed] [Crossref]}

9. Cheng CY, Mruk DD. The blood-testis barrier and its implications for male contraception. Pharmacol Rev. 2012 Jan;64(1):1664. [PubMed] [Crossref]

10. Ambrosini G, Andrisani A, Fiore C, Faggian D, D'Antona D, Ragazzi E, et al. Anti-Helicobacter pylori antibodies in cervical mucus: a new cause of infertility. Eur $J$ Obstet Gynecol Reprod Biol. 2011 Apr;155(2):157-60. [PubMed] [Crossref]

11. Selgrad M, Meyer F, Malfertheiner P. [Helicobacter pylori: short overview on selected data from the history and their value for clinical medicine, in particular, surgery what does the (general/abdominal) surgeon need to know] [in German] Zentralbl Chir. 2014 Aug;139(4): 399-405. [PubMed] [Crossref]

12. Yang SW, Kwon HS, Sohn IS, 
Kim YJ, Hwang HS. Association of VacA- and Cag A-specific Helicobacter pylori strain infection with spontaneous preterm birth. J Matern Fetal Neonatal Med. 2017 Apr; 30(8):995-1000. [PubMed] [Crossref]

13. Sobala GM, Crabtree JE, Dixon MF, Schorah CJ, Taylor JD, Rathbone BJ, et al. Acute Helicobacter pylori infection: clinical features, local and systemic immune response, gastric mucosal histology, and gastric juice ascorbic acid concentrations. Gut. 1991 Nov;32(11): 1415-8. [PubMed] [Crossref]

14. Marietti M, Gasbarrini A, Saracco G, Pellicano R. Helicobacter pylori infection and diabetes mellitus: the 2013 state of the art. Panminerva Med. 2013 Sep;55(3): 277-81. [PubMed]
15. Figura $\mathrm{N}$, Piomboni $\mathrm{P}$, Ponzetto A, Gambera L, Lenzi C, Vaira $\mathrm{D}$, et al. Helicobacter pylori infection and infertility. Eur J Gastroenterol Hepatol. 2002_Jun;14(6):663-9. [PubMed] [Crossref]

16. El-Garem Y, El-Sawy M, Mostafa T. Seminal Helicobacter pylori treatment improves sperm motility in infertile asthenozoospermic men. Urology. 2014 Dec;84(6):134750. [PubMed] [ㄷossref]

17. Caviglia GP, Fagoonee S, Pellicano R. Re: El-Garem et al. Seminal Helicobacter pylori Treatment Improves Sperm Motility in Infertile Asthenozoospermic Men (Urology 2014;84:1347-1350). Urology 2015 May;85(5):1217. [PubMed] [Crossref]
18. Yasin AL, Yasin AL, Basha WS. The Epidemiology of AntiSperm Antibodies Among Couples with Unexplained Infertility in North West Bank, Palestine. J Clin Diagn Res. 2016 Mar;10(3):QC01-3. [PubMed] [Crossref]

19. Fu J, Yao R, Luo Y, Yang D, Cao Y, Qiu Y, et al. Immune Infertility Should Be Positively Diagnosed Using an Accurate Method by Monitoring the Level of Anti-ACTL7a Antibody. Sci Rep. 2016 Mar 9;6:22844. [PubMed] [Crossref]

20. Friberg J. A simple and sensitive micro-method for demonstration of sperm-agglutinating activity in serum from infertile men and women. Acta Obstet Gynecol Scand Suppl. 1974; 36:21-9. [PubMed] [Crossref]

Please cite this article as: Andreeva-Gateva P, Masseva A. Similarly High Seroprevalence of Anti-Helicobacter pylori Antibodies in Men and Women with and without Idiopathic Infertility. J of IMAB. 2021 Jan-Mar;27(1):3497-3501. DOI: https://doi.org/10.5272/jimab.2021271.3497

Received: 11/02/2020; Published online: 05/01/2021

Address for correspondence:

Pavlina Andreeva-Gateva

Department of Pharmacology and Toxicology, Medical University - Sofia, 1, G. Sofiiski str., Sofia, Bulgaria.

E-mail: pandreeva_gateva@outlook.com 